\title{
'Ears of the Lynx' sign: an important and useful MRI clue for diagnosis of hereditary spastic paraplegia (HSP) caused by mutation in SPG 15 gene
}

\author{
Somesh Singh, Amrin Israrahmed, Rana Vishwadeep Mall, Vivek Singh
}

Radiodiagnosis, Sanjay Gandhi Post Graduate Institute of Medical Sciences, Lucknow, Uttar Pradesh, India

\section{Correspondence to} Dr Vivek Singh; singhvivek79@rediffmail.com

Accepted 19 March 2021

\section{DESCRIPTION}

A 23-year-old girl presented with difficulty in walking with stiffness for 7 years. These involved feet and legs at first which progressed proximally; with patient becoming wheelchair bound 2 years ago. 4 years ago, the patient developed urinary urgency. The patient had one episode of altered mentation in form of violent behaviour 3 years back. On further interrogation, there was cognitive decline since 10 years of age. On examination, there was increased tone of muscles of all limbs (Modified Ashworth grade $2 / 4$ ) with exaggerated motor reflexes (grade $3 / 4$ in all limbs). Power in all limbs was normal (grade 5/5). There was no sensory deficit. The

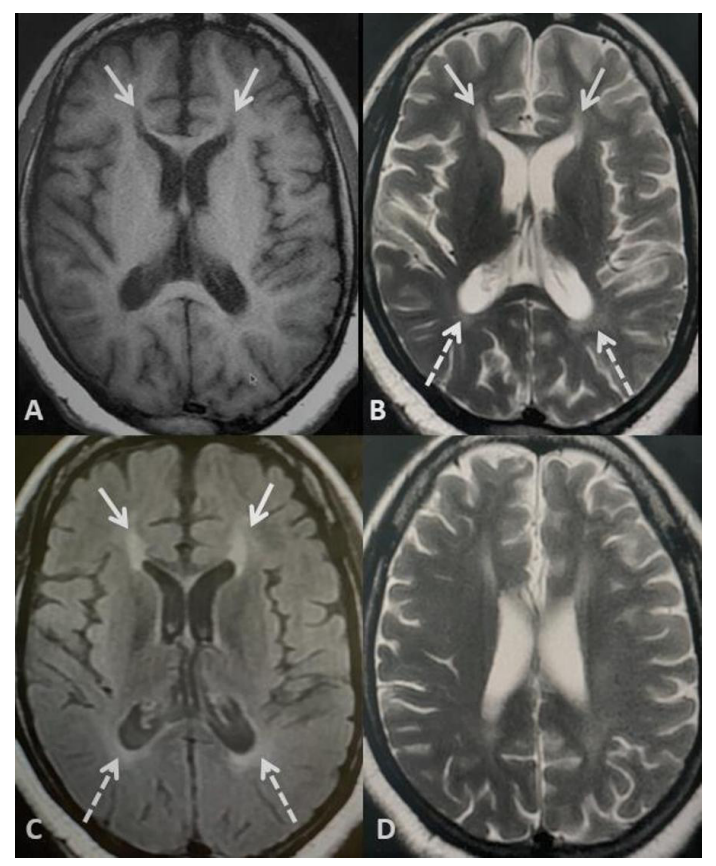

Figure 1 Axial T1 (A), axial T2 (B) and axial T2-FLAIR (C) shows characteristic signal abnormalities involving forceps minor region of genu of corpus callosum (arrows). The signal abnormality appears hypointense on T1 and hyperintense on T2/FLAIR (Fluid attenuation and inversion recovery)and shows a characteristic 'Flame' like morphology and appear very similar to tuft of hair along ears of a lynx: ear of the lynx sign. Additionally, hyperintensities of periventricular white matter, particularly along occipital horns are also seen (broken arrows). Also, axial T2 sections obtained cranially (D) shows mild generalised brain atrophy in form of prominence of sulcal spaces and ventricles for age.

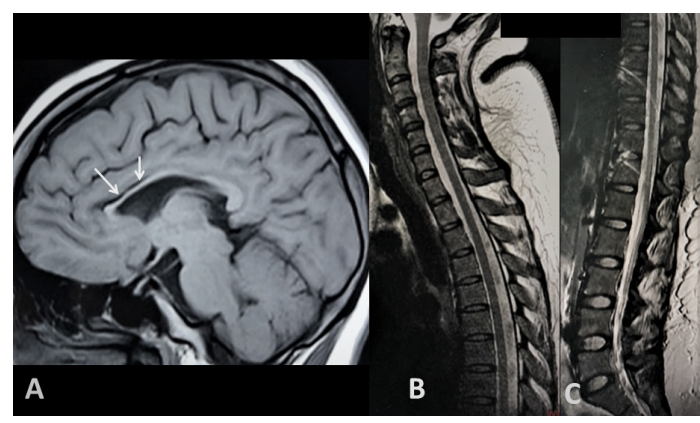

Figure 2 Sagittal T1 image along corpus callosum of brain (A) shows diffuse thinning of entire corpus callosum with more predominant thinning along the anterior aspect of corpus callosum (arrows). Sagittal T2 sequences of entire spine $(B, C)$ shows no significant abnormality of the cord with no features to suggest cord thinning or cord hyperintensities which was confirmed on axial T2 sequences.

patient was diagnosed as insidiously progressive spastic paraparesis. She was born to a nonconsanguineous couple and has an elder brother who has no such complaints. Her hormonal profile, antibody screening, viral panels and cerebrospinal fluid analysis were normal. No oligoclonal bands were found.

An MRI of brain and spine was performed without intravenous contrast administration on a 3T machine (Signa HDxt 3.0T, GE Healthcare, Milwaukee; Wisconsin, USA). MRI showed mild generalised brain atrophy with prominence of ventricles and sulcal spaces. Axial T2 and FLAIR (Fluid attenuation and inversion recovery) sequences showed characteristic changes involving forceps minor region of corpus callosum: appearing hypointense on T1 and hyperintense on T2/FLAIR (figure 1): termed the "ear of the lynx sign' as they closely resemble tuft of hair at top of the ears of lynx. Associated symmetric hyperintensities of periventricular white matter along occipital horns of ventricles were noted. No signal abnormalities along posterior limbs of internal capsules (PLIC) were seen. Sagittal T1W images showed diffuse thinning of corpus callosum which was more prominent anteriorly (figure 2). Spinal cord showed no thinning or hyperintensities within (figure 2). The constellation of imaging features suggested hereditary spastic paraplegia (HSP) and a subsequent genetic test revealed mutation of zinc finger fyve domain-containing protein 
26, ZFYVE26 which encodes for spastizin (SPG 15). The patient was put on supportive treatment and family members counselled for genetic testing.

HSP constitute a group of degenerative disease characterised by progressive limb spasticity. Two types have been described $^{2}$ : 'pure' form presenting only with spastic paraplegia and a 'complicated' form when present with other features such as cognitive changes and altered behaviour. Our patient had the 'complicated form'. HSP has been documented to have various underlying genetic mutations ${ }^{3}$ and can be inherited in various forms: Autosomal dominant, autosomal recessive and X-linked recessive. ${ }^{4}$ Imaging may show characteristic signs as seen in our patient with additional features including atrophy of thalami, hyperintensities of PLICs, thinning of spinal cord and hyperintensities within spinal cord. ${ }^{5}$ 'Ear of the lynx' sign has been shown to have high sensitivity (up to 97.0\%) and high specificity (up

\section{Patient's perspective}

I have been suffering from this debilitating problem since a long time and had consulted many centres for my problem. But the root cause of my problem was never figured out. Finally, after the MRI, additional tests were done and now I have been made aware of the underlying cause of my problems. While I have been counselled about lack of any definitive treatment, I am partially revealed to at least know the cause and happy that because of this my family members will also be tested for this disease.

\section{Learning points}

- Hereditary spastic paraplegia (HSP) is a very rare disorder with myriad of underlying genetic abnormalities. However, imaging can show typical findings regardless of underlying mutation.

- 'Ear of the lynx' sign is a very sensitive as well as specific sign which can be seen in HSP.

- Identifying this scan on MRI should prompt further investigation for HSP. to $100 \%$ ) in diagnosing HSP. $^{6}$ Identifying this sign should prompt further genetic testing for HSP. ${ }^{6}$ A case report has been described where this sign has been encountered in Marchiafava-Bignami syndrome. ${ }^{7}$ However, this report does not mention genetic testing for HSP, and published images are difficult to interpret for HSP.

Twitter Rana Vishwadeep Mall @vishwadeeprana

Contributors SS is the lead author who wrote the manuscript after analysing the literature and was involved in obtaining consent from the patient and following up with genetic testing results after MRI. Al was involved in data analysis in form of researching relevant literature for the manuscript and correlating our findings with those already published in literature. RVM was involved in procurement of images for the manuscript and helped in obtaining the patient's perspective. VS is the corresponding author who oversaw the entire manuscript and guided with relevant wring and inclusion of literature on the subject. All have participated sufficiently in this submission to take public responsibility for its content. The manuscript is approved by all authors.

Funding The authors have not declared a specific grant for this research from any funding agency in the public, commercial or not-for-profit sectors.

Competing interests None declared.

Patient consent for publication Obtained.

Provenance and peer review Not commissioned; externally peer reviewed.

ORCID iD

Vivek Singh http://orcid.org/0000-0001-9543-4773

\section{REFERENCES}

1 Riverol M, Samaranch L, Pascual B, et al. Forceps minor region signal abnormality "ears of the lynx": an early MRI finding in spastic paraparesis with thin corpus callosum and mutations in the spatacsin gene (SPG11) on chromosome 15. J Neuroimaging 2009;19:52-60.

2 Priya S, Siddique N, Das R, et al. Multiparametric 3T MRI evaluation of hereditary spastic paraplegia: a case report. Indian J Radiol Imaging 2016;26:328-31.

3 Kara E, Tucci A, Manzoni C, et al. Genetic and phenotypic characterization of complex hereditary spastic paraplegia. Brain 2016;139:1904-18.

4 Coutinho P, Barros J, Zemmouri R, et al. Clinical heterogeneity of autosomal recessive spastic paraplegias: analysis of 106 patients in 46 families. Arch Neurol 1999:56:943-9.

5 Krabbe K, Nielsen JE, Fallentin E, et al. MRI of autosomal dominant pure spastic paraplegia. Neuroradiology 1997;39:724-7.

6 Pascual B, de Bot ST, Daniels MR, et al. "Ears of the Lynx" MRI Sign Is Associated with SPG11 and SPG15 Hereditary Spastic Paraplegia. AJNR Am J Neuroradiol 2019;40:199-203.

7 Pacheco FT, Rego MM, do Rego JIM, et al. "Ears of the lynx" sign in a marchiafavabignami patient: structural basis and fiber-tracking DTI contribution to the understanding of this imaging abnormality. J Neuroimaging 2014;24:205-7.

Copyright 2021 BMJ Publishing Group. All rights reserved. For permission to reuse any of this content visit

https://www.bmj.com/company/products-services/rights-and-licensing/permissions/

BMJ Case Report Fellows may re-use this article for personal use and teaching without any further permission.

Become a Fellow of BMJ Case Reports today and you can:

- Submit as many cases as you like

- Enjoy fast sympathetic peer review and rapid publication of accepted articles

- Access all the published articles

Re-use any of the published material for personal use and teaching without further permission

Customer Service

If you have any further queries about your subscription, please contact our customer services team on +44 (0) 2071111105 or via email at support@bmj.com.

Visit casereports.bmj.com for more articles like this and to become a Fellow 